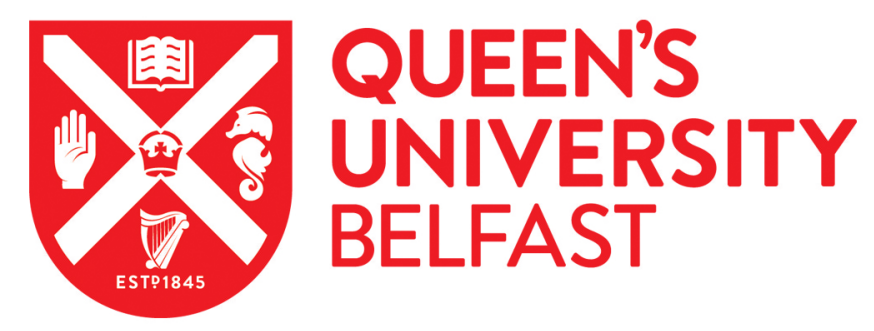

\title{
Manufacturing of novel low-cost adsorbent: Co-granulation of limestone and coffee waste
}

lakovleva, E., Sillanpaa, M., Maydannik, P., Liu, J. T., Allen, S., Albadarin, A. B., \& Mangwandi, C. (2017).

Manufacturing of novel low-cost adsorbent: Co-granulation of limestone and coffee waste. Journal of

Environmental Management. https://doi.org/10.1016/j.jenvman.2017.05.039

Published in:

Journal of Environmental Management

Document Version:

Peer reviewed version

Queen's University Belfast - Research Portal:

Link to publication record in Queen's University Belfast Research Portal

\section{Publisher rights}

Copyright 2017 Elsevier

This manuscript is distributed under a Creative Commons Attribution-NonCommercial-NoDerivs License

(https://creativecommons.org/licenses/by-nc-nd/4.0/), which permits distribution and reproduction for non-commercial purposes, provided the author and source are cited.

\section{General rights}

Copyright for the publications made accessible via the Queen's University Belfast Research Portal is retained by the author(s) and / or other copyright owners and it is a condition of accessing these publications that users recognise and abide by the legal requirements associated with these rights.

Take down policy

The Research Portal is Queen's institutional repository that provides access to Queen's research output. Every effort has been made to ensure that content in the Research Portal does not infringe any person's rights, or applicable UK laws. If you discover content in the Research Portal that you believe breaches copyright or violates any law, please contact openaccess@qub.ac.uk. 
Research article

\title{
Manufacturing of novel low-cost adsorbent: Co-granulation of limestone and coffee waste
}

\author{
Evgenia Iakovleva $^{\mathrm{a}, \mathrm{b}, *}$, Mika Sillanpää ${ }^{\mathrm{a}, \mathrm{c}}$, Philipp Maydannik ${ }^{\mathrm{a}}$, Jiang Tao Liu ${ }^{\mathrm{b}}$, Stephen Allen ${ }^{\mathrm{b}}$, \\ Ahmad B. Albadarin ${ }^{\mathrm{b}, \mathrm{d}}$, Chirangano Mangwandi ${ }^{\mathrm{b}}$ \\ ${ }^{a}$ Laboratory of Green Chemistry, School of Engineering Science, Lappeenranta University of Technology, Sammonkatu 12, FI-50130, Mikkeli, Finland \\ b School of Chemistry and Chemical Engineering, Queen's University Belfast, Belfast, BT9 5AG, Northern Ireland, UK \\ ${ }^{c}$ Department of Civil and Environmental Engineering, Florida International University, 10555, West Flagler Street, Miami, FL, 33174, USA \\ ${ }^{d}$ School of Natural Sciences, Bernal Institute, University of Limerick, Limerick, Ireland
}

\section{A R T I C L E IN F O}

\section{Article history:}

Received 7 April 2016

Received in revised form 2 May 2017

Accepted 10 May 2017

Available online $\mathrm{xxx}$

Keywords:

Wet granulation

Bio-waste

Methylene blue

Orange II

\begin{abstract}
A B S T R A C T
Limestone and coffee waste were used during the wet co-granulation process for the production of efficient adsorbents to be used in the removal of anionic and cationic dyes. The adsorbents were characterized using different analytical techniques such as XRD, SEM, FTIR, organic elemental analysis, the nitrogen adsorption method, with wettability, strength and adsorption tests. The adsorption capacity of granules was determined by removal of methylene blue (MB) and orange II (OR) from single and mixed solutions. In the mixed solution, co-granules removed $100 \%$ of $\mathrm{MB}$ and $85 \%$ of OR. The equilibria were established after 6 and $480 \mathrm{~h}$ for $\mathrm{MB}$ and $\mathrm{OR}$, respectively.
\end{abstract}

(C) 2016 Published by Elsevier Ltd.

\section{Introduction}

During recent decades, researches considered solid wastes as sources of biofuels (Schröder, 2015), fertilizers (Nishio and Nakashimada, 2013), composite materials (Pavla, 2011) and low-cost adsorbents for water treatment (Kaushik et al., 2009; Bhatnagar et al., 2015; Iakovleva and Sillanpää, 2013). The main problems regarding water treatment are the minimization and reuse of processed water, and cost saving including a reduction in energy consumption. Despite a quarter century of studies, these problems of solid and liquid wastes management are as relevant today as 25 years ago, when the term "industrial ecology" was introduced (Smith et al., 2015).

For example, Finland is first in the world for coffee consumption and has about 50M kg coffee wastes per year (Ojaniemi, 2010). Coffee wastes are mostly used as a source for bio-energy and fertilizers (Cruz et al., 2015; Adi and Noor, 2009). In some research papers, coffee waste has been used as biosorbents for the removal of acid dye (Gupta and Suhas, 2009; Rafatullah et al., 2010; Lafi et al., 2014; Roh et al., 2012; Kyzas et al., 2012), organics (Al-Zaben and Mekhamer, 2013; Lafi and Hafiane, 2015; Rossmann et al., 2012)

\footnotetext{
* Corresponding author. Laboratory of Green Chemistry, School of Engineering Science, Lappeenranta University of Technology, Sammonkatu 12, FI-50130, Mikkeli, Finland.

Email address: evgenia.iakovleva@lut.fi (E. Iakovleva)
}

and metal ions from aqueous solutions (Azouaou et al., 2010; Boonamnuayvitaya et al., 2004; Ching et al., 2011; Kaikake et al., 2007; Oliveira et al., 2008; Pujol et al., 2013). Coffee waste has a high $\mathrm{C} / \mathrm{N}$ ratio, and contains carboxylic group (Cruz et al., 2015) ensuring high efficiency for metal ions removal due to chelates formation (Adi and Noor, 2009; Lafi et al., 2014). Therefore, the coffee waste could be used as potentially effective sorbent for various pollutants, including metal ions. In order to test properties of new adsorbent Methylene Blue (MB) and Orange II (OR) were used as model acidic and basic pollutants, respectively. Various functional groups such as amino, hydroxyl, carboxyl and sulfate on the bio-waste surface, which can act as binding sites for acidic and basic dyes, help to increase the adsorption effect (Adegoke and Bello, 2015; Kyzas et al., 2012). Clay and siliceous materials show high affinity for pollutants in acidic solution as a scavenger through an ion-exchange process (Iakovleva et al., 2015).

A combination of limestone and coffee waste might improve the removal efficiency of pollutants and ensure neutralization of the acidic water, based on the ion-exchange reactions on the surface of combined sorbent.

Adsorbents must have certain properties to be suitable for industrial use. The combined sorbents must be resistant to water, must not stick together, and should retain the properties of the original materials (Albadarin et al., 2014; Mangwandi et al., 2014). Granulation of two different materials was chosen as a way to produce a uniform dual adsorbent. There are some requirements of the material to be 
produced, including segregation of the powder particles, uniform granules, their wettability, strength and stability in the solutions. The adsorbent should be stable to the transportation as well. The main parameters of the granulation process are process variables such as processing time, impeller speed and formulation variables such as particles size and choice of binder. Homogeneous materials are granulated uniformly, and produce pellets of the similar size and composition. Our choice of binder was made taking into account results of previous studies (Mangwandi et al., 2014). The widely used carboxymethylcellulose binder was not suitable in this research as it is water soluble; the resultant granules would disintegrate when coming into contact with the waste water. It seems that polyvinyl acetate (PVAc) might give better results in the granulation of dissimilar materials and it is water insoluble.

The main aim of this research was to develop a low-cost and effective sorbent for water treatment of both anionic and cationic pollutants, as well as neutralization of acidic water. Limestone seemed to be one of the most suitable candidates for acidic water neutralization as well as for removal of a number of pollutants. Limestone is a commercial material for acidic neutralization of water and agriculture's grounds (Iakovleva et al., 2015; Mangwandi et al., 2014). This work proposes the novel approach to the treatment of waste water from cationic and anionic dyes using the same sorbent. In order to improve the adsorption properties of the limestone, a combination of limestone and coffee wastes will be used in this research. In this study, coffee waste and limestone were co-granulated using PVAc as binder. The strength and wettability of granules, as well as their reuse and resistance to liquid solutions were determined. Adsorption properties of new adsorbents were tested for their ability to remove MB and OR. The competition of removal of both cationic and basic dyes from complex liquid was examined.

\section{Raw materials}

Limestone was provided by Killwaughter Chemical Ltd UK. The CW was collected from the cafeteria at Queen's University Belfast, Rami cafeteria of Mikkeli and Green Chemistry Laboratory of Lappeenranta University of Technology. Before use, CW was washed with distilled water, and oven dried for $12 \mathrm{~h}$ at $60^{\circ} \mathrm{C}$.

Polyvinyl acetate (PVAc) and acetone by MERCK UK were used as a binder in the granulation process. Solution of PVA was prepared by dissolving a known mass of the $\mathrm{PVA}_{\mathrm{C}}$ (from 10 to $40 \%$ ) in acetone. The mixture was stirred for about $20 \mathrm{~min}$ at $60{ }^{\circ} \mathrm{C}$ to obtain a homogenous solution. The viscosities of the binder solutions were determined by the Haake Viscotester C.

\section{Co-granules production}

A small bench scale high shear granulator (KENWOOD KM070 (Japan) was used for the granulation of materials. The known mass of limestone powder and coffee waste were added to the mixer and mixed without binder for $60 \mathrm{~s}$. The known value of binder was added to the powder during the next $30 \mathrm{~s}$ without stopping the rotator. The mixing of powder was performed at an impeller speed of $490 \mathrm{rpm}$ and binding occurred within $60 \mathrm{~s}$ until the formation of granules.

\section{Characterization of raw materials and co-granules}

\subsection{Spectral and physics characterization}

The particle size distribution was determined using dispersion analyzer LUMiSizer 610/611 (GmbH). The measurements were performed thrice.

The chemical composition and organic elemental analysis of raw materials were determined with an energy dispersive X-ray fluorescent (ED XRF) analyzer X-Art (Joint Stosk Company Comita, St. Petersburg, Russia) and CHNS-O analyzer (Flash 2000 Elemental Analyzer, Thermo Fisher Scientific, UK), respectively.

FTIR spectra of raw materials and granules were recorded with a Bruker Vertex 70v spectrometer. Spectra were collected in the mid infrared region (4000-400 $\mathrm{cm}^{-1}$ ) averaging 124 scans with $4 \mathrm{~cm}^{-1}$ resolution. Samples were prepared by the standard $\mathrm{KBr}$ pellet methods.

The samples were characterized with nitrogen sorption at $196{ }^{\circ} \mathrm{C}$ using TriStar 3000 (Micromeritics Inc., USA). The specific surface area of samples was calculated using the Brunauer-Emmett-Teller (BET) theory.

Microstructure of the raw and produced materials was examined using a scanning electron microscope (SEM, Nova Nano SEM 200, FEI Company). The experiment was carried out at low vacuum condition in secondary electron mode. For the analysis, samples were covered with a gold layer.

In order to study the effect of binder viscosity on the co-granulation process, different granulation experiments were carried out using binder solution of different concentrations whilst maintaining the other processing conditions constant. All experiments were carried out at room temperature $\left(24^{\circ} \mathrm{C}\right)$ with mixing time and speed of $2 \mathrm{~min}$ and $490 \mathrm{rpm}$, respectively.

The effect of the $\mathrm{L}$ and $\mathrm{CW}$ ratio on the granulation process was studied using different amounts of each material. The granules were dried for $12 \mathrm{~h}$ at $80^{\circ} \mathrm{C}$. The dried granules were separated according to size by sieving. The percentage of co-granules in each size range was calculated by following equation:

$$
n=\left(\frac{m_{i}}{m_{t}}\right) \times 100 \%
$$

where $m_{t}$ and $m_{i}$ are initial and total the measure range mass of co-granules, respectively.

Granules strength was measured from diametric compression of the single granules using previously described method using Eq. (2).

$$
\sigma=2.8 \times\left(\frac{F_{i}}{\pi D^{2}}\right)
$$

where $F_{i}$ (Newton) is compressive force during testing of granules strength, $i$ is number of tests, $D(\mathrm{~mm})$ is granules diameter.

Granules wettability was tested by mixing a known mass of granules with water at ambient temperature for $72 \mathrm{~h}$. After testing, all granules were oven dried for $12 \mathrm{~h}$ at $80^{\circ} \mathrm{C}$. The strength and size of granules were determined before and after wettability tests.

\subsection{Batch adsorption experiments}

Sorption tests of pollutants were conducted by mixing a known weight (from 0.5 to $40 \mathrm{~g} \mathrm{~L}^{-1}$ ) of L, CW, PVAc and LCW with $15 \mathrm{ml}$ 
of synthetic solution of MB and OR. The concentration of dyes on the synthetic solution ranged from 5 to $20 \mathrm{mg} \mathrm{L}^{-1}$. The experimental solutions were shaken by a shaker ST5 (IKA KS 4000i Control) from 1 to $720 \mathrm{~h} .10 \mathrm{~mL}$ solutions were taken from flasks at known time intervals and filtered using a $0.20 \mu \mathrm{m}$ diameter polypropylene syringe filter. For determination of final concentration of dyes, $2 \mathrm{~mL}$ of solution was taken and determined by UV/Vis spectrometer (Lambda 45 PerkinElmer Instrument) at wavelength 664 and 486 for MB and OII, respectively.

The percentage adsorption was calculated as:

$$
\% \text { Adsorption }=\frac{\left(C_{i}-C_{t}\right)}{C_{i}} \times 100
$$

where $\mathrm{A}$ is adsorption, $\mathrm{C}_{\mathrm{i}}$ and $\mathrm{C}_{\mathrm{t}}\left(\mathrm{mg} \mathrm{L}^{-1}\right)$ are the pollutants concentrations in the initial and treated solutions, respectively.

\section{Results and discussion}

\subsection{The chemical composition of materials}

The chemical compositions of the raw materials are presented in Table 1. These results were collected with ED-XRF and organic elemental analysis. The limestone contains about $20 \%$ calcium and $40 \%$ silicon. The coffee waste consists mainly of organic components,

Table 1

Chemical composition of raw materials (XRF and organic elemental analysis).

\begin{tabular}{lll}
\hline Element & $\mathrm{L}(\mathrm{w} \%)$ & $\mathrm{CW}(\mathrm{w} \%)$ \\
\hline $\mathrm{Al}$ & 1.5 & $<1$ \\
$\mathrm{C}$ & 3.3 & 60 \\
$\mathrm{Ca}$ & 21.3 & $<1$ \\
$\mathrm{H}$ & - & 6 \\
$\mathrm{~K}$ & 0.25 & $<1$ \\
$\mathrm{~N}$ & - & 3 \\
$\mathrm{O}$ & 52.7 & 25 \\
$\mathrm{~S}$ & 0.1 & $<1$ \\
$\mathrm{Si}$ & 42 & 5 \\
\hline
\end{tabular}

such as lignin, nitrogenous compounds, fibers, etc. (Narita and Inouye, 2014).

\subsection{The particle size distribution}

The average value of particle size distribution has been reported in Fig. 1. The coffee waste particles are approximately ten times larger than the limestone particles. Their diameters range from 100 to $1000 \mu \mathrm{m}$ and are less uniform than limestone powder. More than ten times difference in particle size of the two materials might cause problems during the binding process. Also, great difference in particles size might complicate uniform granulation. Therefore, the selection of the ratio of the two raw materials presents three challenges. The first is to choose the concentration of binders for sufficient strength at which the granules will withstand long exposure to water. The second is to choose the appropriate ratio of the two materials with different particle size. And the last is to produce granules with sufficient surface area of sorbents for efficient pollutant removal.

\subsection{Co-granules production}

The optimal concentration of binder was chosen by granulation of limestone and coffee waste separately. The data of binder solution viscosity and matrix of granulation test are presented in Tables 2 and 3. After preliminary tests the optimal binder concentration of $30 \%$ was chosen. The preliminary co-granules tests demonstrated that, for the preparation of the largest granules $(>1000 \mu \mathrm{m})$ with high wettability, the best combination was 7 parts limestone to 3 parts coffee waste. This ratio was used for further experiments. The chosen materials ratio and binder concentration produced the greatest number of granules with particle size from 1 to $2 \mathrm{~mm}$. These granules have better stability upon contact with water and remain approximately the same size and strength (Table 2). These co-granules should be used for waste water treatment over an extended testing time.

\subsection{Spectral characteristics}

Spectroscopic studies of limestone in the mid-infrared region with FTIR analysis confirms the results of XRD studies. The compounds

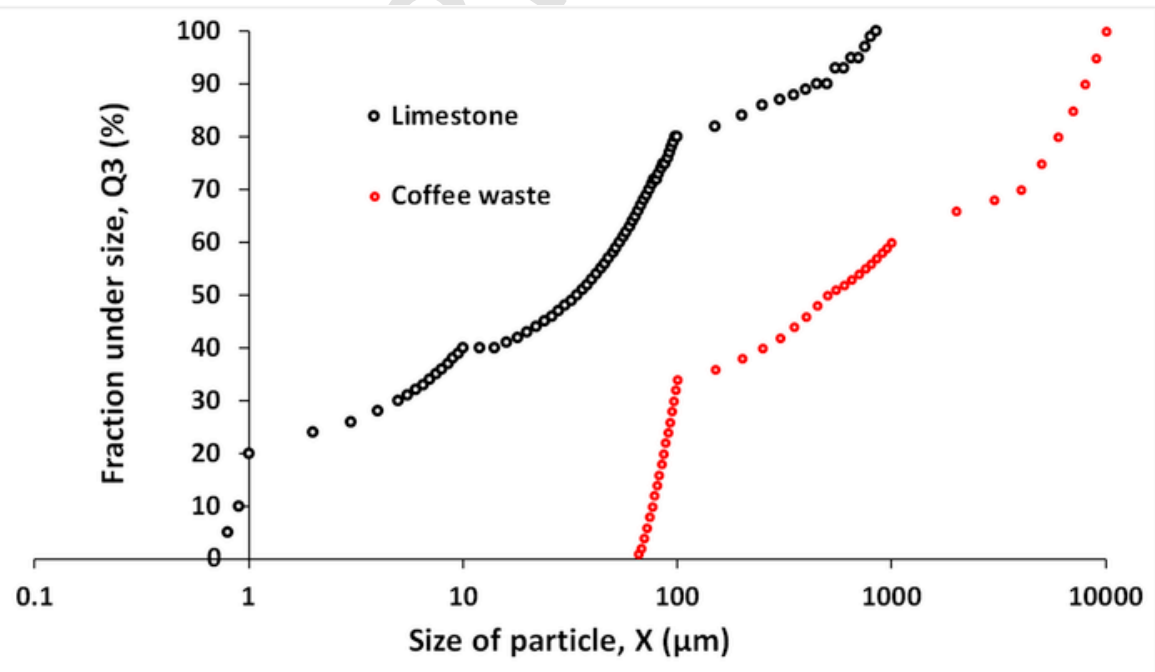

Fig. 1. Particle size distribution of limestone and coffee waste. 
Table 2

Viscosity of binder solutions with various concentration of PVA.

\begin{tabular}{ll}
\hline $\mathrm{C}_{\mathrm{PVA}}(\%)$ & $\mu(\mathrm{mPa} \cdot \mathrm{c})$ \\
\hline 10 & 1.4 \\
15 & 13 \\
20 & 37 \\
25 & 52 \\
30 & 72 \\
35 & 111 \\
40 & 157 \\
\hline
\end{tabular}

Table 3

Mass fraction of raw materials, size and strength of granules before and after wettability test.

\begin{tabular}{|c|c|c|c|c|c|c|}
\hline \multirow[t]{2}{*}{$\begin{array}{l}\text { Mass } \\
\text { fraction of } \\
\text { limestone }\end{array}$} & \multirow[t]{2}{*}{$\begin{array}{l}\text { Mass } \\
\text { fraction } \\
\text { of } \\
\text { coffee } \\
\text { waste }\end{array}$} & \multicolumn{3}{|c|}{$\begin{array}{l}\text { Size of granules, before } \\
\text { wettability test }(\%)\end{array}$} & \multirow[t]{2}{*}{$\begin{array}{l}\text { Strength of } \\
\text { granules } \\
\text { before } \\
\text { wettability } \\
\text { test (MPa) }\end{array}$} & \multirow[t]{2}{*}{$\begin{array}{l}\text { Strength of } \\
\text { granules } \\
\text { after } \\
\text { wettability } \\
\text { test (MPa) }\end{array}$} \\
\hline & & $1-2 \mathrm{~mm}$ & $0.5-1 \mathrm{~mm}$ & $\leq 0.5 \mathrm{~mm}$ & & \\
\hline 1.0 & 0.0 & 28 & 49 & 23 & 28 & 21 \\
\hline 0.75 & 0.25 & 25 & 27 & 48 & 28 & 10 \\
\hline 0.70 & 0.30 & 60 & 30 & 10 & 35 & 14 \\
\hline 0.60 & 0.40 & 49 & 47 & 4 & 12 & 2 \\
\hline 0.50 & 0.50 & 40 & 53 & 7 & 10 & 3 \\
\hline 0.40 & 0.60 & 36 & 45 & 19 & 11 & 3 \\
\hline 0.30 & 0.70 & 30 & 46 & 24 & 9 & 2 \\
\hline 0.25 & 0.75 & 28 & 48 & 24 & 27 & 39 \\
\hline 0.0 & 1.0 & 40 & 53 & 7 & 28 & 42 \\
\hline
\end{tabular}

of calcium, carbonate, and silicone were detected with both analyses (Tables 1 and 4). Various organic compounds remained in coffee waste even after extraction, as confirmed by XRF, FTIR and organic elemental analysis. The results of spectroscopic analysis show that co-granules were composed of nearly all functional groups from the two raw materials. This indicates that the pre-mixing of raw materials was uniform and the binder did not block the functional groups which are involved in the adsorption process.

The coffee waste has very low specific surface area and therefore is not presented. Specific surface area of the limestone and co-granules is about $2.2 \mathrm{~m}^{2} \mathrm{~g}^{-1}$ and only $0.4 \mathrm{~m}^{2} \mathrm{~g}^{-1}$, respectively (Figs. 2 and 3 ). The low surface area of coffee waste and coating of the coffee waste particles with PVAc could cause sharp decrease of co-granules specific area. However, the spectroscopic analysis shows complex structure of materials. SEM images are presented in Fig. 4.

Table 4

FTIR spectrum data for raw materials and granules.

\begin{tabular}{llll}
\hline Compound & $\mathrm{WN}_{\mathrm{L}}\left(\mathrm{cm}^{-1}\right)$ & $\mathrm{WN}_{\mathrm{CW}}\left(\mathrm{cm}^{-1}\right)$ & $\mathrm{WN}_{\mathrm{LCW}}\left(\mathrm{cm}^{-1}\right)$ \\
\hline $\mathrm{C} \equiv \mathrm{O}_{3}$ & 719 & + & + \\
$\mathrm{C}-\mathrm{H}$ & - & 808 & - \\
$\mathrm{Ca}-\mathrm{C} \equiv \mathrm{O}_{3}$ & 871 & - & + \\
$\mathrm{Si}-\mathrm{O}$ & 1100 & 1029 & + \\
$\mathrm{S}=\mathrm{O}_{2}$ & - & 1158 & - \\
$\mathrm{C}-\mathrm{O}$ & - & 1239 & + \\
$\mathrm{Ca}-\mathrm{C} \equiv \mathrm{O}_{3}$ & 1377 & - & + \\
$\mathrm{Ca}-\mathrm{O}$ & - & 1518 & + \\
$\mathrm{R}=\mathrm{C}=\mathrm{O}$ & - & 1654 & - \\
$\mathrm{R}=\mathrm{C}=\mathrm{O}$ & - & 1743 & + \\
$\mathrm{Ca}-\mathrm{O}$ & 2512 & - & + \\
$\mathrm{R}-\mathrm{O}-\mathrm{H}$ & - & 2853 & + \\
$\mathrm{Si}-\mathrm{O}-\mathrm{H}$ & $3200-3700$ & 2923 & + \\
$\mathrm{N}-\mathrm{H}$ & - & 3294 & + \\
$\mathrm{R}-\mathrm{O}-\mathrm{H}$ & - & 3329 & + \\
\hline
\end{tabular}

The surface structure of coffee waste is underdeveloped and almost flat, as was confirmed by BET method data (Fig. 4a). The structure of limestone is highly developed (Fig. 4b). The size of most particles is less than a micrometer. The surface of co-granules inherited a complex structure of limestone (Fig. 4c). Most likely, this is due to the fact that the fine particles of limestone are distributed on the flat surface area of coffee waste and set up agglomerations. For the purpose of this study, it is important that the functional groups of $\mathrm{CW}$ were available for pollutants during the removal process. The presence of functional groups on the surface area of co-granules was confirmed with FTIR (Table 4).

\subsection{Synthetic dye solution treatment}

The removal of MB and OR with novel combinative granulated sorbents from single synthetic solution and mixture was researched in this work. The adsorption properties of co-granules and their materials were studied separately to understand possible removal mechanisms. The possible effect of binder on the removal of pollutants has been eliminated by the adsorption test using PVAc for treatment of solution from both dyes.

\subsubsection{Optimization of adsorbent amount and contact time}

The optimal amount of adsorbents and efficient contact time with an initial concentration of dyes $2 \mathrm{mg} \mathrm{L}^{-1}$ are shown in Figs. 5 and 6.

The equilibrium of the systems was reached with the concentration of each adsorbents at $2 \mathrm{~g} \mathrm{~L}^{-1}$ for both dyes. The maximum removal of MB, $100 \%$, and OR, $85 \%$ removal, was found after 6 and $480 \mathrm{~h}$, respectively. Removal of both dyes was relatively higher with co-granules, as compared to each material individually. This could be explained by a smaller number of functional groups on the surface area of the co-granules capable of removing anions, compared with cations.

\subsubsection{Effect of $p H$ and possible removal mechanism}

The impact of solution $\mathrm{pH}$ on the dyes adsorption process has been investigated by increasing the initial $\mathrm{pH}$ from 2 to 10 , while the initial dyes concentration, temperature, co-granules dosage and contact time were kept constant at $5 \mathrm{mg} \mathrm{L}^{-1}, 25 \pm 2{ }^{\circ} \mathrm{C}, 2 \mathrm{~g} \mathrm{~L}^{-1}$ and $60 \mathrm{~min}$, respectively (Fig. 7).

The study of the effect of $\mathrm{pH}$ on the removal of cationic and anionic dyes confirms the results of previous researchers (Albadarin et al., 2011; Ramesh et al., 2005; Kyzas et al., 2012; Lafi and Hafiane, 2015; Lafi et al., 2014). MB was removed from the solution more efficiently at high $\mathrm{pH}$ as the adsorption mechanisms associated with the formation of a complex between the positively charged ions and negatively charged dye ion on the adsorbent surface. While the adsorption capacity of OR increases in basic medium by electrostatic interaction between negatively charged dye ions and positively charged cell of co-granules surface (Lafi and Hafiane, 2015).

The possible removal mechanism of cationic and anionic dyes is ion-exchange between co-granules surface and pollutants. In case of OR there might be two mechanisms: ion-exchange between the positively charged ions on the surface of the co-granules and anionic dyes and physisorption between OR and carbon which is part of the coffee waste. For the removal of OR by ion-exchange mechanism the ionic strength of the solution should provide an exchange between the similar sodium cations, or between calcium and sodium (Fig. 8).

The process of adsorption of dyes is reversible. This was confirmed by desorption studies performed using solutions at different $\mathrm{pH}$; the dyes were easily desorbed from the adsorbent surfaces. Concentrated hydrochloric acid and sodium hydroxide, were used for the 


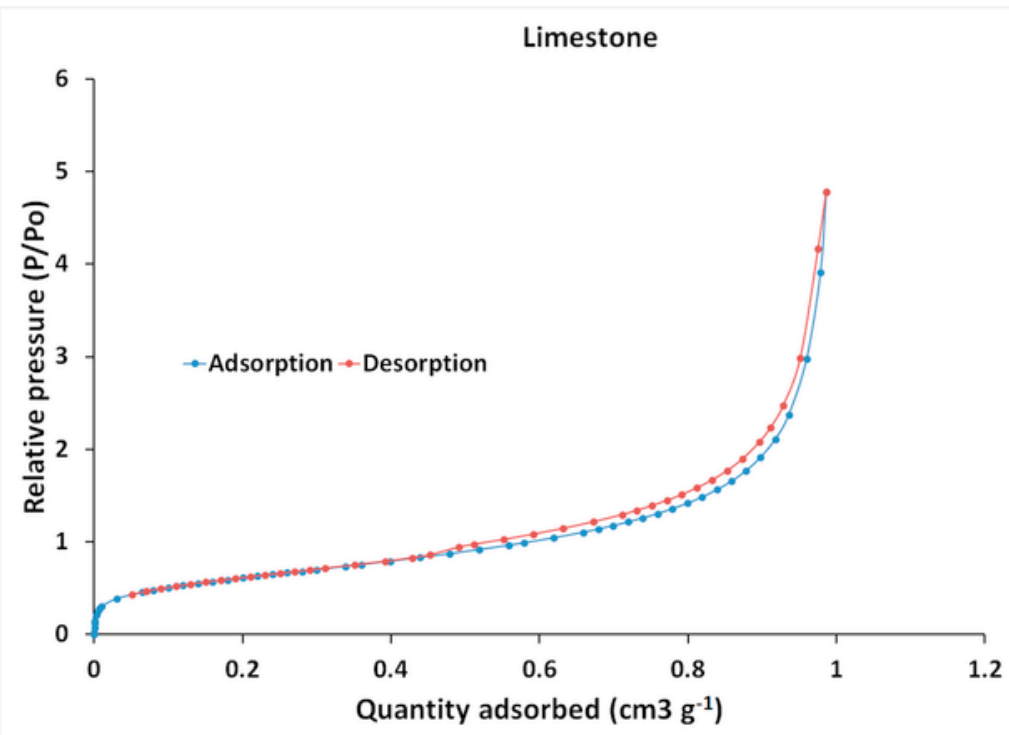

Fig. 2. Adsorption-desorption analysis of limestone with $\mathrm{N}_{2}$.

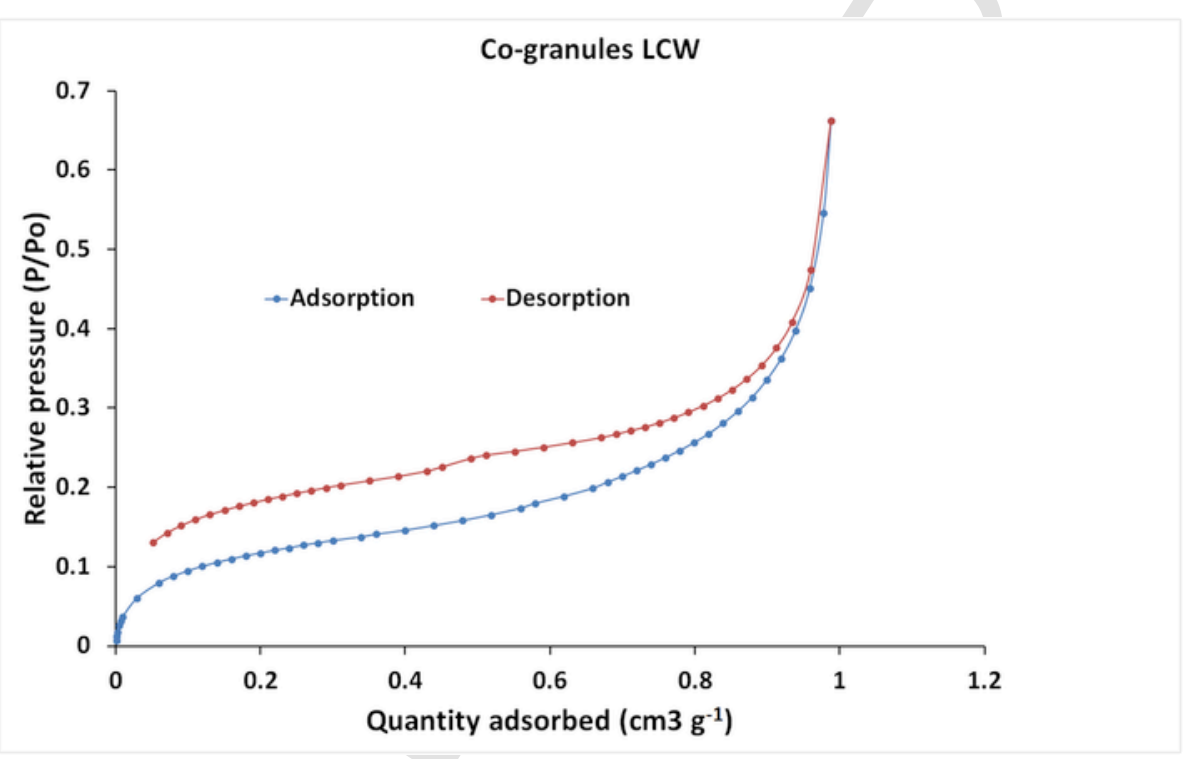

Fig. 3. Adsorption-desorption analysis of co-granules with $\mathrm{N}_{2}$.

desorption of MB and OR, respectively. Experiments showed that desorption process of MB was $100 \%$, while desorption efficiency of OR was only $50 \%$. The reusing experiments showed that the developed co-granules can be used only once.

\subsection{3. $M B$ and $O R$ ions competition}

Competition between $\mathrm{MB}$ and $\mathrm{OR}$ during the adsorption on co-granules was observed. The presence of MB reduced the removal of OR from $85 \%$ to $60 \%$. During experiments it was found that the amount of removed MB remained at $100 \%$ and equilibrium was reached after $24 \mathrm{~h}$. However, the removal of OR was $60 \%$ and did not increase even after $720 \mathrm{~h}$. By contrast, desorption process of OR into solution was observed and measured to be about $20 \%$. It could be explained by the fact that the limestone increased $\mathrm{pH}$ of initial solution to $\mathrm{pH} 8$ during the removal process. Decreasing concentration of $\mathrm{OH}^{-}$ could change the positive charge surface of co-granules to negative, thereby reducing the sorption capacity of dye anions (Kyzas et al., 2012).

\section{Conclusion}

The novel efficient co-granules from $\mathrm{CW}$ and $\mathrm{L}$ for purifying acidic wastewater containing dyes were produced. The co-granules showed more affinity to acidic than to basic pollutants, and percentage removal from complex solution was 100 and 60, respectively. However, decreasing of $\mathrm{pH}$ solution to 2 , allowed to increase to $85 \%$ removal of basic pollutants. The strength and resistance to wettability of co-granules makes them suitable for various types of water treatment, including passive and column methods. Use of these novel materials would reduce not only bio-waste amount, but would also benefit the water treatment with efficient and low-cost adsorbents. 

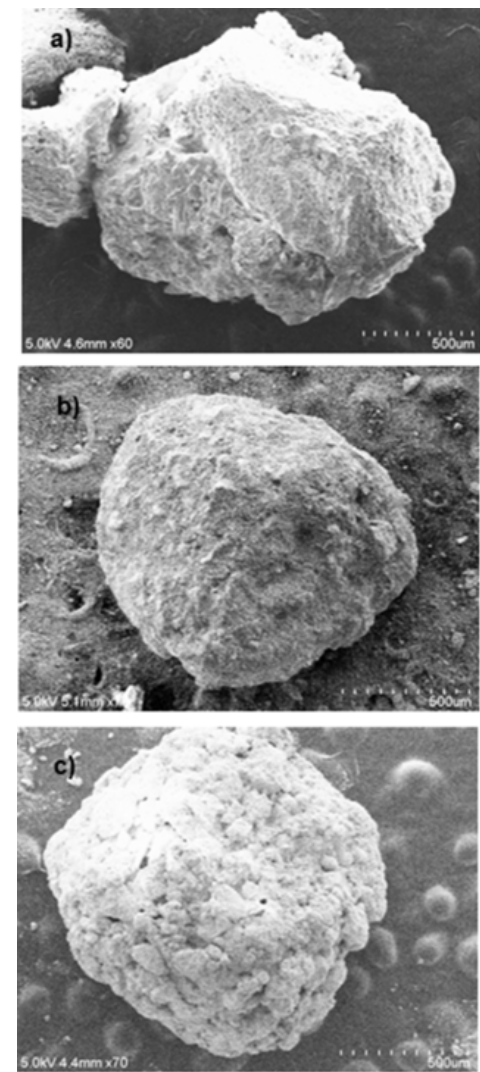
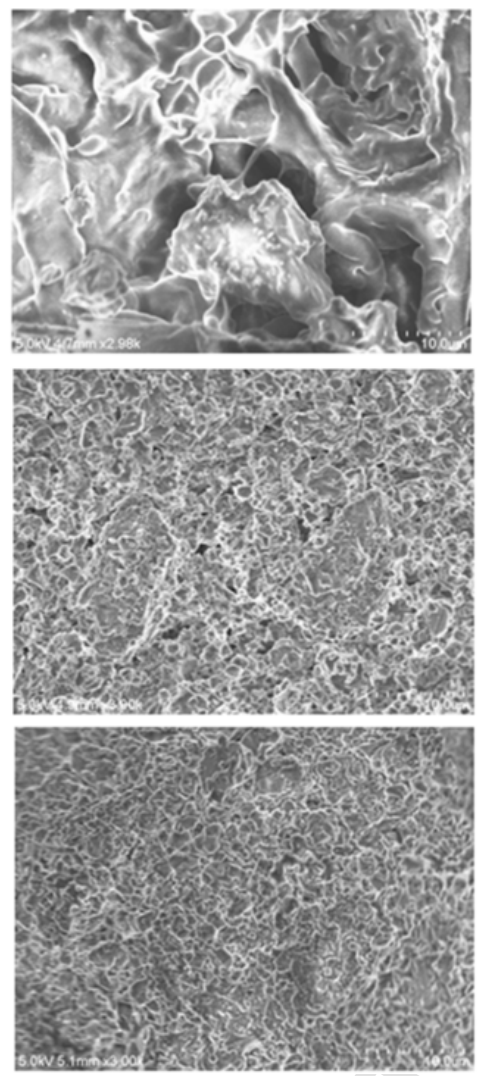

Fig. 4. SEM image of CW (a), L (b) and LCW (c).
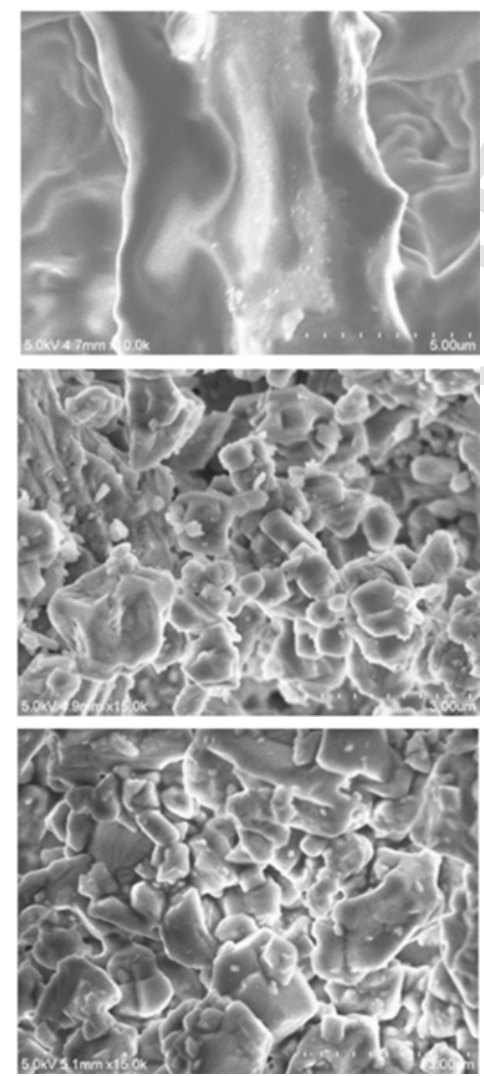

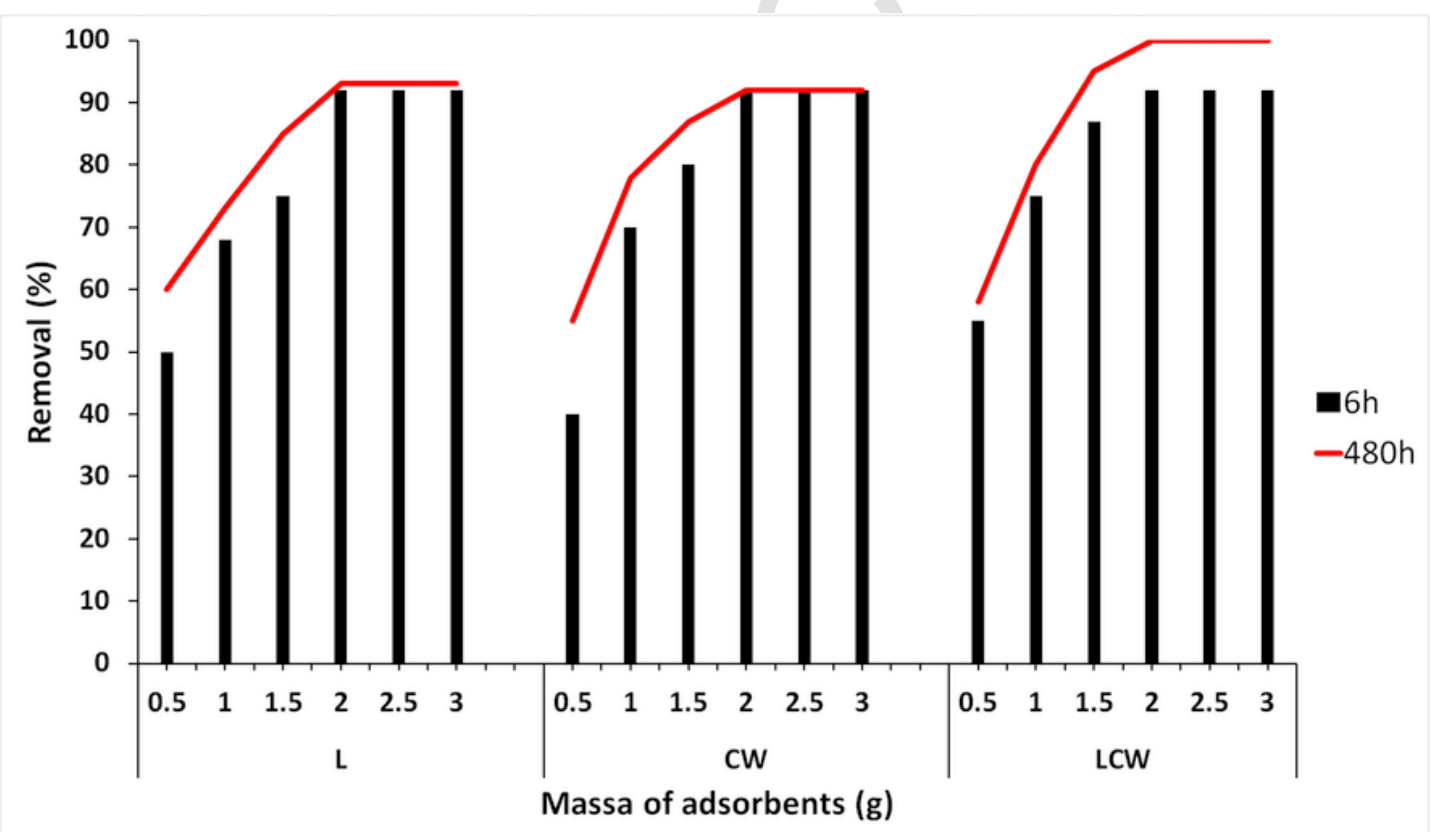

Fig. 5. Optimal conditions for the removal of $\mathrm{MB}$ with limestone, coffee waste and their co-granules. 


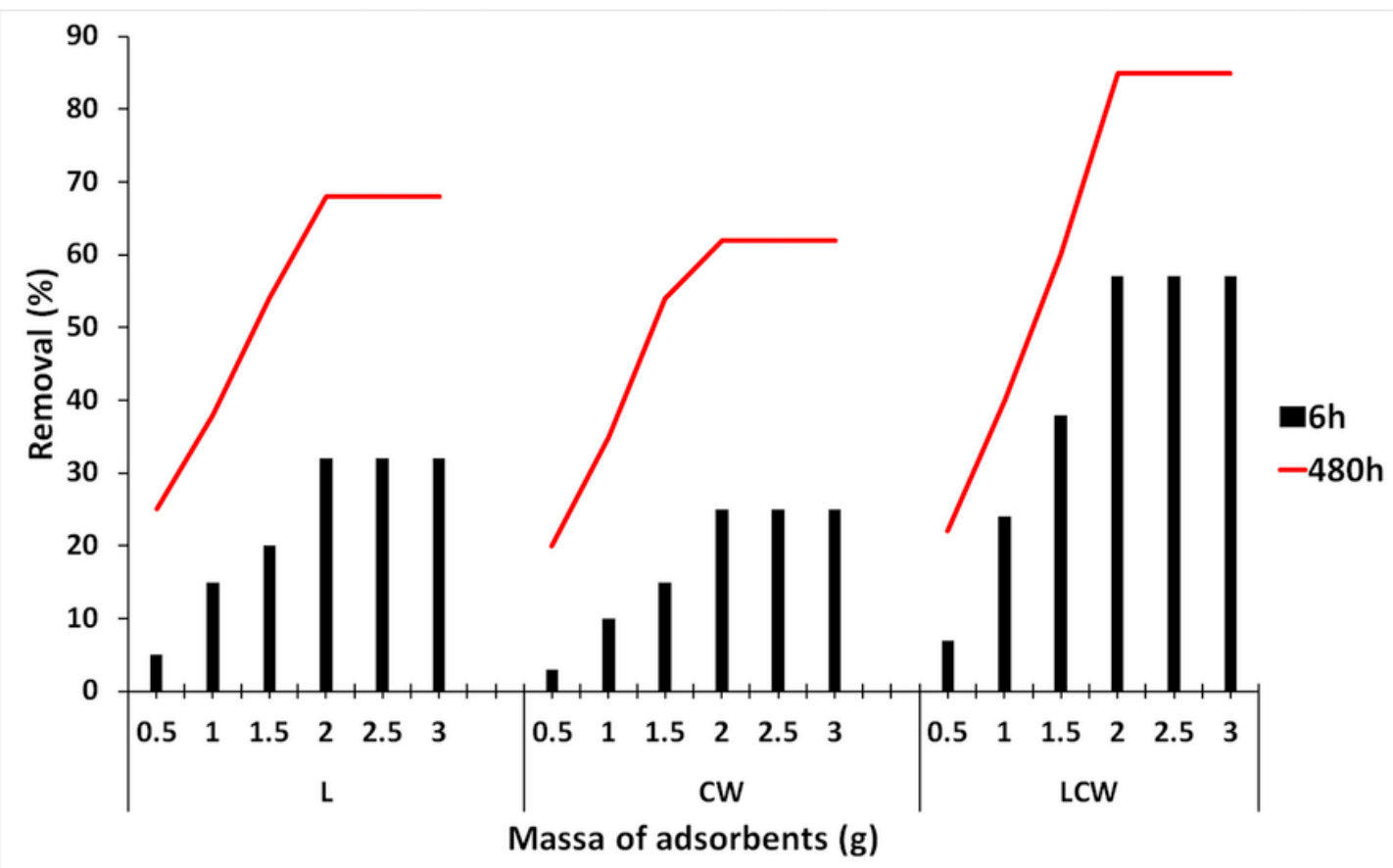

Fig. 6. Optimal conditions for the removal of OR with limestone, coffee waste and their co-granules.

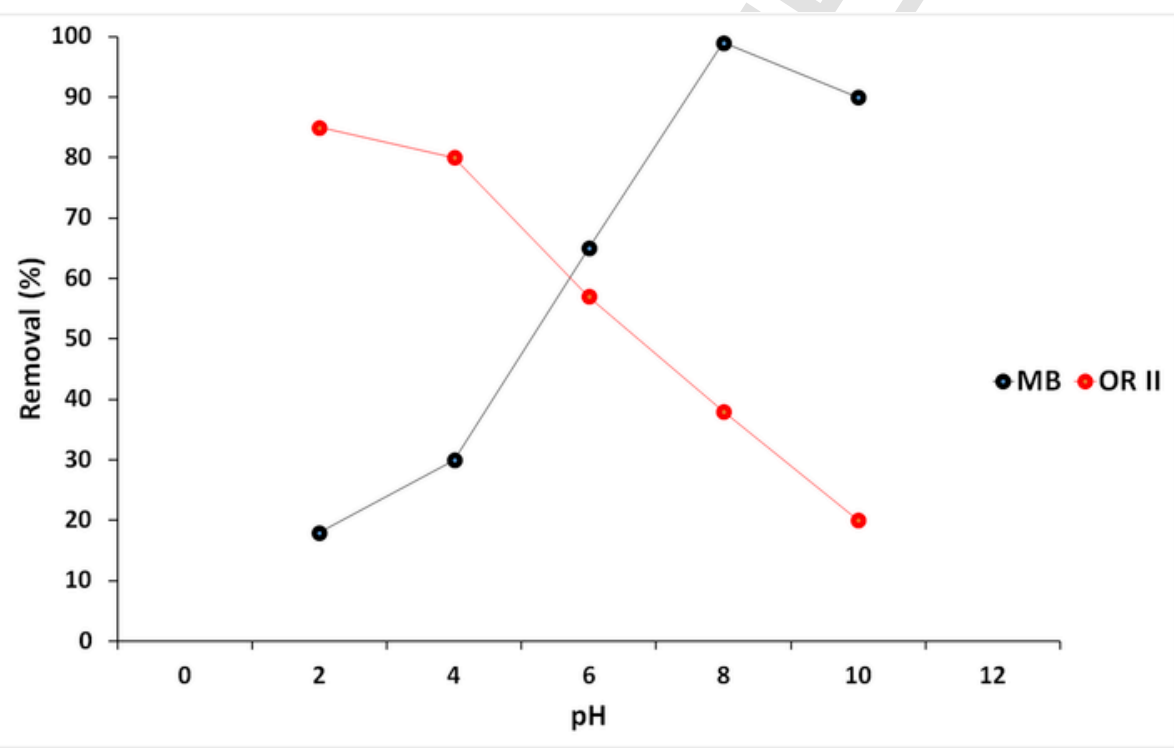

Fig. 7. Effect of $\mathrm{pH}$ on the adsorption amount of $\mathrm{MB}$ and $\mathrm{OR}$ with co-granules.

\section{Acknowledgements}

The authors acknowledge Finnish Funding Agency for Technology and Innovation (TEKES) for financial support. The authors are grateful to Dr. Vergisova for constructive review of this paper and Feiping Zhao for drawing of molecules. Cafeteria at Queen's University Belfast and Rami cafeteria of Mikkeli is thanked for collecting coffee waste. 


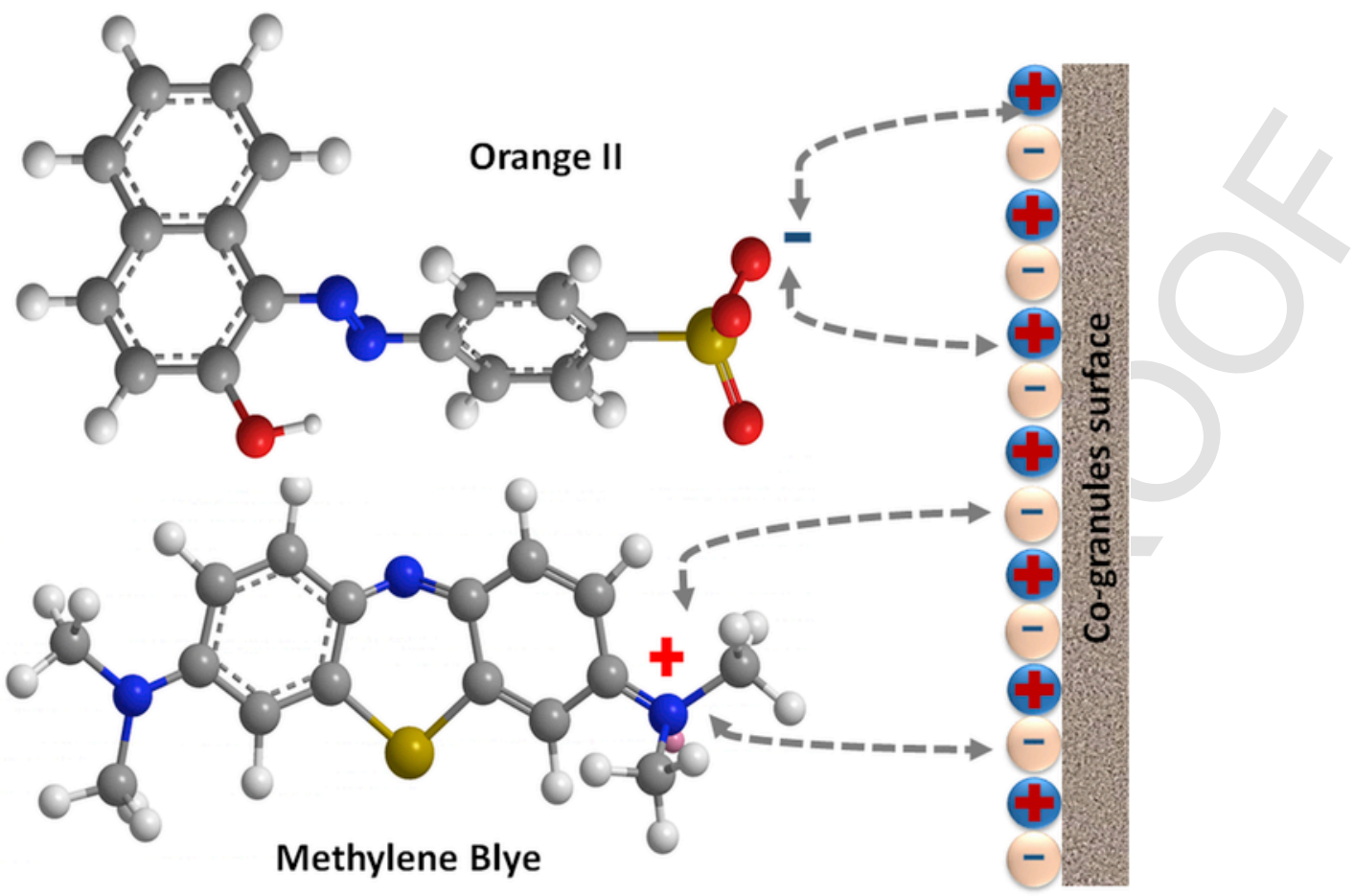

Fig. 8. Ion-exchange mechanism of MB and OR removal.

\section{References}

Adegoke, K.A., Bello, O.S., 2015. Dye sequestration using agricultural wastes as adsorbents. Water Resour. Ind. 12, 8-24. http://dx.doi.org/10.1016/j.wri.2015.09. 002 .

Adi, A.J., Noor, Z.M., 2009. Waste recycling: utilization of coffee grounds and kitchen waste in vermicomposting. Bioresour. Technol. 100, 1027-1030. http://dx.doi.org/ 10.1016/j.biortech.2008.07.024.

Albadarin, Ahmad B., Mangwandi, C., Walker, G.M., Allen, S.J., Ahmad, M.N., 2011 Biosorption characteristics of sawdust for the removal of Cd(II) ions: mechanism and thermodynamic studies. Chem. Eng. Trans. 24, 1297-1302.

Albadarin, Ahmad B., Mo, J., Glocheux, Y., Allen, S., Walker, G., Mangwandi, C., 2014. Preliminary investigation of mixed adsorbents for the removal of copper and methylene blue from aqueous solutions. Chem. Eng. J. 255, 525-534.

Al-Zaben, M.I., Mekhamer, W.K., 2013. Removal of 4-chloro-2-methyl phenoxy acetic acid pesticide using coffee wastes from aqueous solution. Arab. J. Chem. http://dx.doi.org/10.1016/j.arabjc.2013.05.003.

Azouaou, N., Sadaoui, Z., Djaafri, A., Mokaddem, H., 2010. Adsorption of cadmium from aqueous solution onto untreated coffee grounds: equilibrium, kinetics and thermodynamics. J. Hazard. Mater. 184, 126-134. http://dx.doi.org/10.1016/j. jhazmat.2010.08.014.

Bhatnagar, A., Sillanpää, M., Witek-Krowiak, A., 2015. Agricultural "waste peels" as versatile biomass for water purification - a review. Chem. Eng. J. 270, 244-271. http://dx.doi.org/10.1016/j.cej.2015.01.135.

Boonamnuayvitaya, V., Chaiya, C., Tanthapanichakoon, W., Jarudilokkul, S., 2004 Removal of heavy metals by adsorbent prepared from pyrolyzed coffee residues and clay. Sep. Purif. Technol. 35, 11-22. http://dx.doi.org/10.1016/ S1383-5866(03)00110-2.

Ching, S.L., Yusoff, M.S., Aziz, H.A., Umar, M., 2011. Influence of impregnation ratio on coffee ground activated carbon as landfill leachate adsorbent for removal of total iron and orthophosphate. Desalination 279, 225-234. http://dx.doi.org/10. 1016/j.desal.2011.06.011.

Cruz, R., Mendes, E., Torrinha, , Morais, S., Pereira, J.A., Baptista, P., Casal, S., 2015 Revalorization of spent coffee residues by a direct agronomic approach. Food Res. Int. 73, 190-196. http://dx.doi.org/10.1016/j.foodres.2014.11.018.

Gupta, V.K., Suhas, 2009. Application of low-cost adsorbents for dye removal - a review. J. Environ. Manage. 90, 2313-2342. http://dx.doi.org/10.1016/j.jenvman. 2008.11.017.

Iakovleva, E., Mäkilä, E., Salonen, J., Sitarz, M., Sillanpää, M., 2015. Industrial products and wastes as adsorbents for sulphate and chloride removal from synthetic alkaline solution and mine process water. Chem. Eng. J. 259, 364-371. http://dx.doi org/10.1016/j.cej.2014.07.091.
Iakovleva, E., Sillanpää, M., 2013. The use of low-cost adsorbents for wastewater purification in mining industries. Environ. Sci. Pollut. Res. 20, 7878-7899. http://dx. doi.org/10.1007/s11356-013-1546-8.

Kaikake, K., Hoaki, K., Sunada, H., Dhakal, R.P., Baba, Y., 2007. Removal characteristics of metal ions using degreased coffee beans: adsorption equilibrium of cadmium(II). Bioresour. Technol. 98, 2787-2791. http://dx.doi.org/10.1016/j.biortech. 2006.02.040

Kaushik, C.P., Tuteja, R., Kaushik, N., Sharma, J.K., 2009. Minimization of organic chemical load in direct dyes effluent using low cost adsorbents. Chem. Eng. J. 155, 234-240. http://dx.doi.org/10.1016/j.cej.2009.07.042.

Kyzas, G.Z., Lazaridis, N.K., Mitropoulos, A.C., 2012. Removal of dyes from aqueous solutions with untreated coffee residues as potential low-cost adsorbents: equilibrium, reuse and thermodynamic approach. Chem. Eng. J. 189-190, 148-159. http: //dx.doi.org/10.1016/j.cej.2012.02.045.

Lafi, R., Hafiane, A., 2015. Removal of methyl orange (MO) from aqueous solution using cationic surfactants modified coffee waste (MCWs). J. Taiwan Inst. Chem. Eng. http://dx.doi.org/10.1016/j.jtice.2015.06.035.

Lafi, Ridha, Fradj, Anouar, Hafiane, Amor, Hammed, B.H., 2014. Coffee waste as potential adsorbent for the removal of basic dyes from aqueous solution. Environ. Eng. 31, 2198-2206.

Mangwandi, C., Albadarin, A.B., JiangTao, L., Allen, S., Walker, G.M., 2014. Development of a value-added soil conditioner from high shear co-granulation of organic waste and limestone powder. Powder Technol. 252, 33-41. http://dx.doi.org/ 10.1016/j.powtec.2013.10.039.

Narita, Y., Inouye, K., 2014. Review on utilization and composition of coffee silverskin. Food Res. Int. 61, 16-22. http://dx.doi.org/10.1016/j.foodres.2014.01.023.

Nishio, N., Nakashimada, Y., 2013. Food Industry Wastes, Food Industry Wastes. Elsevierhttp://dx.doi.org/10.1016/B978-0-12-391921-2.00007-X.

Ojaniemi, T., 2010. Coffee as a Finnish Institution [WWW Document]. Finnish Inst. URL https://www15. uta.fi/FAST/FIN/GEN/to-coffe.html.

Oliveira, W.E., Franca, A.S., Oliveira, L.S., Rocha, S.D., 2008. Untreated coffee husks as biosorbents for the removal of heavy metals from aqueous solutions. J. Hazard. Mater. 152, 1073-1081. http://dx.doi.org/10.1016/j.jhazmat.2007.07.085.

Pavla, T. (Ed.), 2011. Advances in Composite Materials - Analysis of Natural and Man-made Materials. InTechhttp://dx.doi.org/10.5772/728.

Pujol, D., Bartrolí, M., Fiol, N., Torre, F., de la, Villaescusa, I., Poch, J., 2013. Modelling synergistic sorption of $\mathrm{Cr}(\mathrm{VI}), \mathrm{Cu}(\mathrm{II})$ and $\mathrm{Ni}(\mathrm{II})$ onto exhausted coffee wastes from binary mixtures $\mathrm{Cr}(\mathrm{VI})-\mathrm{Cu}(\mathrm{II})$ and $\mathrm{Cr}(\mathrm{VI})-\mathrm{Ni}(\mathrm{II})$. Chem. Eng. J. 230, 396-405. http://dx.doi.org/10.1016/j.cej.2013.06.033.

Rafatullah, M., Sulaiman, O., Hashim, R., Ahmad, A., 2010. Adsorption of methylene blue on low-cost adsorbents: a review. J. Hazard. Mater. 177, 70-80. http://dx.doi. org/10.1016/j.jhazmat.2009.12.047. 
Ramesh, A., Lee, D.J., Wong, J.W.C., 2005. Thermodynamic parameters for adsorption equilibrium of heavy metals and dyes from wastewater with low-cost adsorbents. J. Colloid Interface Sci. http://dx.doi.org/10.1016/j.jcis.2005.04.084.

Roh, Jinkyu, Umh, Ha Nee, Yoo, Chang Mo, Rengaraj, Selvaraj, Lee, Byunghwan, Kim, Y., 2012. Waste coffee-grounds as potential biosorbents for removal of acid dye 44 from aqueous solution. Environ. Eng. 29, 903-907.

Rossmann, M., de Matos, A.T., Abreu, E.C., e Silva, F.F., Borges, A.C., 2012. Performance of constructed wetlands in the treatment of aerated coffee processing waste- water: removal of nutrients and phenolic compounds. Ecol. Eng. 49, 264-269. http://dx.doi.org/10.1016/j.ecoleng.2012.08.017.

Schröder, T., 2015. The biobased economy - a book review. J. Clean. Prod. 110, http:// dx.doi.org/10.1016/j.jclepro.2015.05.136.

Smith, R.L., Sengupta, D., Takkellapati, S., Lee, C.C., 2015. An industrial ecology approach to municipal solid waste management: I. Methodology. Resour. Conserv. Recycl. 104, 311-316. http://dx.doi.org/10.1016/j.resconrec.2015.04.005. 